\title{
Determining the Relationship between Floral Initiation and Source-Sink Dynamics of Tomato Seedlings Affected by Changes in Shading and Nutrients
}

\author{
Rui Wang \\ Hortultural College, Shenyang Agricultural University, National \& Local \\ Joint Engineering Research Center of Northern Hortultural Facilities Design \\ \& Application Technology (Liaoning), China; and Institute of Vegetable and \\ Floriculture Science, National Agriculture and Food Research Organization, \\ Japan
}

\author{
Yuqing Gui \\ Assessment Center of Jiangsu Provincial Department of Agriculture and \\ Rural Affairs, China
}

Tiejun Zhao

Faculty of Agro-Food Science, Niigata Argo-Food University, Japan

Masahisa Ishii
Institute for Rural Engineering, National Agriculture and Food Research
Organization, Japan

Masatake Eguchi

Institute of Vegetable and Floriculture Science, National Agriculture and Food Research Organization, Japan

Hui Xu and Tianlai Li

Hortultural College, Shenyang Agricultural University, National \& Local Joint Engineering Research Center of Northern Hortultural Facilities Design \& Application Technology (Liaoning), China

\section{Yasunaga Iwasaki \\ Institute of Vegetable and Floriculture Science, National Agriculture and Food Research Organization, Japan}

Additional index words. accumulation, bud number, early induction condition, leaf area, light

Abstract. Floral initiation is an important transition point from vegetative growth to reproductive growth in tomatoes and is known to be affected by light intensity, temperature, and nutrients. However, the regulation between flower formation and environmental factors, including nutrient conditions, due to source-sink dynamics (supply and demand of photoassimilates) is seldom documented. To evaluate the effects of light intensity and nutrition conditions on prefloral formation and development, dynamic floral characteristics during development were fitted with sigmoidal logistic curves under four light treatments with shading nets in two nutrient conditions. Source activity and sink strength were altered, which caused differences in the floral positions, length of floral shoots, floral initiation dates, and leaf numbers under the different treatments. Accumulated light acts upstream of nutrition supply during the formation of buds and leads to the accumulation of carbohydrates in source organs. Leaf area reached $\approx 500 \mathrm{~cm}^{2}$, and dry matter weights reached $\approx \mathbf{g}$ in each treatment until the flowering day, revealing that some level of photoassimilates are necessary for floral initiation. Both days to flowering and bud number were highly correlated with daily light integral (DLI) from 6 to 12 days before anthesis, which means this period is important for anthesis in tomato. Our results highlight regulation of the transition from vegetative growth to reproductive growth by tomato seedlings due to environmental factors and nutrients. A better understanding of communication between source organs and sink organs during floral initiation response to different environments is expected to provide management strategies for greenhouse tomato production.

Flower initiation is an important transition from vegetative growth to reproductive growth and is also a determinate stage in plant yield formation (Blackman, 2017). From the first stage of petal growth to the full flower opening, large amounts of soluble carbohydrates are known to accumulate (Corbesier et al., 1998; Yap et al., 2008; Yu et al., 2015). The growth environment and nutrients act as the driving force for photosynthesis in realizing energy accumulation. Under nonstress conditions, light is not only a source to regulate flower initiation but also acts as a direct energy resource for photosynthetic accumulation (Kinet, 1977). It has been established that the light intensity and light interception by the plant canopy directly leads to sucrose in leaves and overall productivity of plants (Gotoh et al., 2018; Heuvelink and Marcelis, 1996).

In natural environments or field production conditions, the plant must integrate complex environmental factors to adjust flower initiation combined with environmental factors and nutrients. The effect of nutrient availability on physiological growth (i.e., leaf area, dry matter accumulation, shoot branching, bud number, and root growth) has been extensively reported (Gao et al., 2018; Xu et al., 2010). Nutrient deficiency, especially nitrogen $(\mathrm{N})$ reduces the extension of leaf area, as a consequence of a prolonged time of dry matter accumulation (Chen et al., 2018; Yasuoka et al., 2018). On the other hand, environmental variations and the growth of plants also affect the absorption and distribution of nutrients (Gonzalez-Real et al., 2008). However, most studies focus on the effects at a single time point; there are few reports examining the effects of light and nutrients on plant growth or on accumulation and translocation of photoassimilates during flower initiation.

Plants rely on the energy gained via photosynthesis in source organs, mainly mature leaves, to form carbohydrates and translocate photoassimilates, mainly sucrose, to sink organs such as young leaves, roots, stems, flowers, and fruits for their utilization. Sucrose is the main sugar that moves through the phloem from leaves (source) to provide soluble carbohydrates to developing flowers (sink). The translocation of photoassimilates depends on source supply and sink demand as shown in Fig. 1. The increase of glucose and fructose concentrations in petals has been observed in many species, such as rose, lily, and tulips (Kumar et al., 2008). Moreover, the content of key enzymes associated with flower initiation increases with sucrose, and the balance of source production and sink strength of carbon is a key factor in flower development (Roldán et al., 1999). Crop productivity can be enhanced by high photosynthesis and nutrients, or high sink activity to compete for more photoassimilates, which were mainly found in fruits such as oilseed rape, grape, tomato, and cucumber ( $\mathrm{Li}$ et al., 2015; Marion et al., 2014). In fact, the mechanism of source-sink communication of a plant during its life span, including flower initiation and development, has seldom been reported.

Due to changes in environmental factors and nutrients, the source-sink balance regulates sugar mobilization, which is involved in the formation of number and morphology 


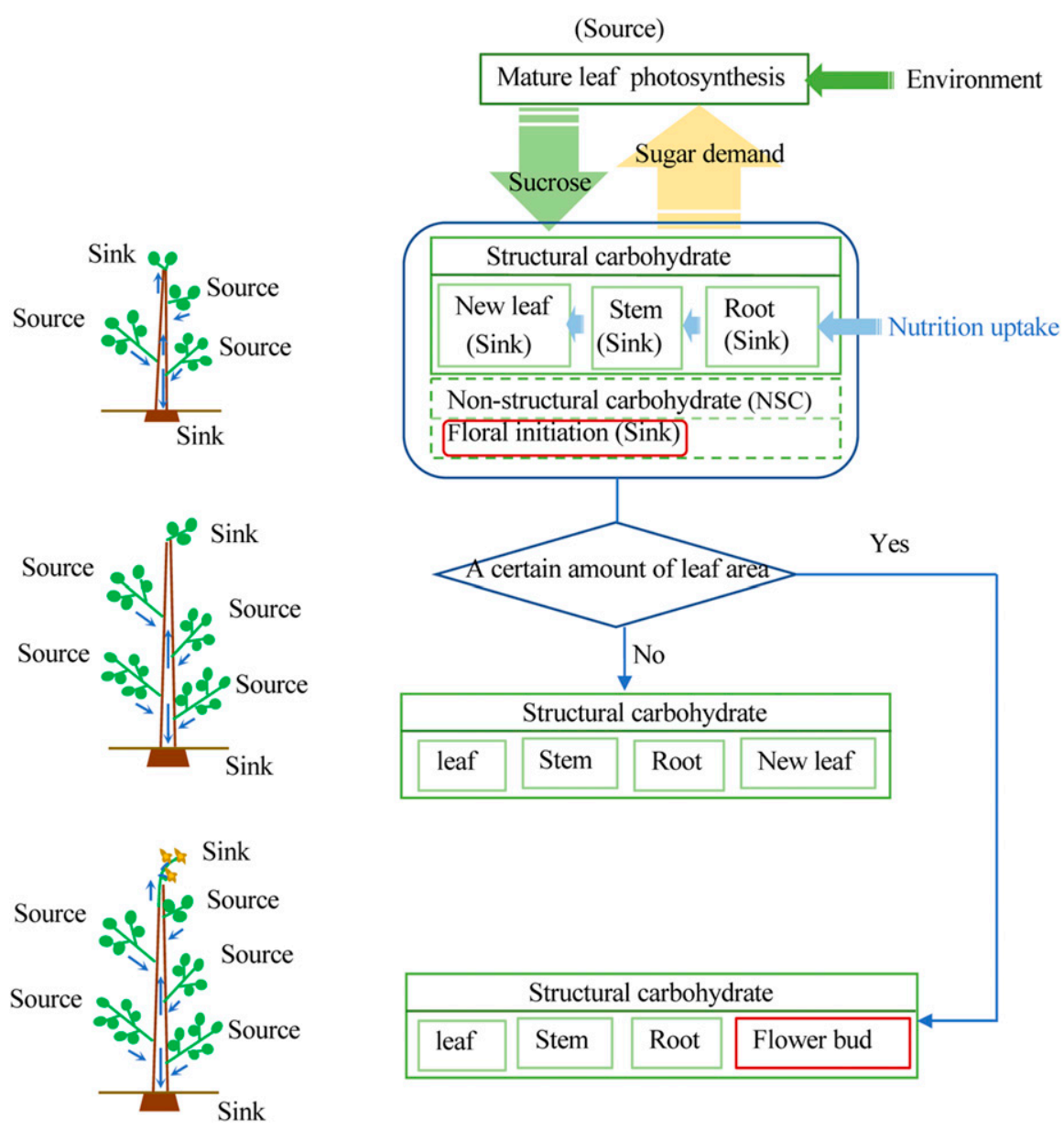

Fig. 1. The metabolic pathway correlation analysis of bud numbers and other factors.

characteristics of sink organs such as leaves, stems, roots, and flowers (Dileman and Heuvelink, 1992; NeSmith, 1997; Sezgin et al., 2006; Villalobos and Ritchie, 1992). Under heat stress, the whole-plant carbohydrate partitioning of rice at anthesis was changed, and the sugars acted as a signal molecule to mediate the source-sink relationship (Zhang et al., 2018). Under suboptimal light conditions, plants showed a strong demand for carbohydrates, and the sourcelimiting was obvious (Christiaens et al., 2016). In supplemental lighting treatment, variations of light environment have an effect on bud abscission (Fudano et al., 2009).

Tomato is one of the most important horticultural crops grown in greenhouses because it achieves a whole season of production in the greenhouse. Most ornamental plants flower

Received for publication 26 Nov. 2019. Accepted for publication 31 Dec. 2019.

Published online 25 February 2020

We thank Dr. Limi Okushima, Dr. Tomoharu Yamaguchi, and Mr. Ryota Tsuchiya for discussions and useful comments on the manuscript.

R.W. is the corresponding author. E-mail: ruiwangsyau@ 126.com

This is an open access article distributed under the CC BY-NC-ND license (https://creativecommons. org/licenses/by-nc-nd/4.0/). aim of this study was to quantify the effects of light intensity and nutrients on the accumulation of photoassimilates and dry matter and to investigate the source-sink relationship during flower initiation.

\section{Materials and Methods}

Greenhouse conditions and plant material. The experiment was conducted from 20 Aug. 2018 to 10 Oct. 2018 in a greenhouse located at the institute of Vegetable and Floriculture Science, National Agriculture and Food Research Organization, Japan (E 140.03, N 36.04). Mini tomato seedlings (Solanum lycopersicum, 'Chika'; Takii \& Co., Ltd. Kyoto, Japan), a Japanese variety, were used as the experimental plant. In common production greenhouse, the bud number is $\approx 12$ to 20 . The seed trays were placed in a seedling growth chamber (Nae Terrace, Mitsubishi Plastics Agri Dream, Tokyo, Japan) and were grown at air temperatures of $28^{\circ} \mathrm{C}$ and $20^{\circ} \mathrm{C}$ (day and night) for $3 \mathrm{~d}$. Seedlings were then grown in another growth chamber at air temperatures of $24{ }^{\circ} \mathrm{C}$ and $20^{\circ} \mathrm{C}$ (day and night) for 2 weeks until two true leaves extended, after which the plants were transplanted into containers (15 $\mathrm{cm} \times 37 \mathrm{~cm} \times 25 \mathrm{~cm})$ filled with nutrient solution (Otsuka House Solution A; OAT Agrio Co., Ltd, Tokyo, Japan) on 10 Sept. 2018. Four light treatments were used including a full light control, and $30 \%, 50 \%$, and $70 \%$ shading ratios for four plots. Shading was achieved using three different shading nets (SW-30, SW-50, SW-70; DIO Chemicals, Ltd., Japan) (Fig. 2) hung over the tomato seedlings at a height of $\approx 1.5 \mathrm{~m}$. In each plot, there were two nutrient treatments including EC $0.6 \mathrm{dS} \cdot \mathrm{m}^{-1}$ for the low fertilizer concentration and EC $1.8 \mathrm{dS} \cdot \mathrm{m}^{-1}$ for the high fertilizer concentration. Eight treatments were designated as FH, FL, LH, LL, MH, ML, $\mathrm{HH}$, and HL, as shown in Table 1.

Shading treatments started between 10 Sept. and 25 Sept., which is the main period for the first floral formation. The variations of daily temperature and DLI were shown as in Fig. 3. All plots were well watered to avoid water stress. Standard commercial tomato management practices were used for the whole growing period.

Throughout the experimental period, air temperatures and nutrient solution temperatures were recorded by thermometers (TR-4; T\&D Corporation, Japan). Photosynthetic photon flux density (ML-020P; EKO, Japan) above the crop canopy was measured with a data logger (GL200; Graphtec, Japan). Data were continuously recorded every $10 \mathrm{~min}$.

Destructive measurements were based on four replicate plants; leaf area (LI-3100A; Li-Cor, Lincoln, NE), and dry matter accumulation was sampled every $7 \mathrm{~d}$. Nondestructive measurements of leaf area were recorded by a depth sensor (Kinect ver. 1, Microsoft, Redmond, WA) every 2 d. Eight plants were randomly selected until termination of floral bud differentiation from each plot 
every day to measure leaf number, count the number of floral buds, and observe floral development.

Model description. In each treatment, the number of floral buds was modeled as a binomial variable. Curves for floral development of the dynamic increase in floral bud number were fitted using sigmoidal logistic curves. The temperature and DLI were independent variables and the floral growth traits were used as the dependent variable. The

$$
y=\frac{K}{1+a^{*} e^{-b x}},
$$

where $K$ represents the maximum number of floral buds; $a$ and $b$ are logarithmic function parameters; and $y$ is the number of floral buds.

In addition, the results of logistic regression analysis were expressed for the growth of total dry matter and leaf area. The parameters in this logistic equation were evaluated using a $t$ test with high significance ( $P \leq$ $0.01, \mathrm{n}=4)$.

\section{Results}

Dynamic changes of floral development after the shading treatment. Logistic models adequately described the floral initiation as a function of accumulated thermal time from transplanting date, as shown in Fig. 4. Time to floral initiation was delayed by the shading treatments. In the four light treatments-full light and $30 \%, 50 \%$, and $70 \%$ shade-the cumulative temperatures until floral initiation was $550,600,650$, and $700{ }^{\circ} \mathrm{C}$, respectively. Floral blooming finally ended at $>900{ }^{\circ} \mathrm{C}$. The floral bud number varied among shading rates and nutrient concentrations. At the same shading rate due to the fertilizer treatments, the average number of floral buds per plant in the full light control decreased from 20 to 10 ; in $30 \%$ shading, from 14 to 12 ; in $50 \%$ logistic equation is as follows:

shading, from 13 to 11 ; and in $70 \%$ shading, from 10 to 8 . The maximum number of floral buds was 30 per plant in FH treatment and the minimum number of floral buds was nine per plant in LL treatment. The goodness of fit by the logistic equation was evaluated by the adjusted coefficient of determination $\left(R^{2}>\right.$ $0.97, \mathrm{n}=8$ ).

The effect of shading on the average floral number under high fertilizer was greater than that under low fertilizer conditions. In the full light treatment, the average number of floral buds in both fertilizer conditions varied from 20 to 12 , a decrease of $40 \%$, while in the $70 \%$ shading treatment, it changed from 10 to 8 , a $20 \%$ decease.

Effects of leaf area and dry mater on floral bud initiation. Leaf areas increased with cumulative temperatures according to the exponential function and varied among all treatments, as shown in Fig. 5. The growth of leaf area in high fertilizer treatment floral initiation was faster than that in low fertilizer treatment. At the same cumulative temperature, due to the variation of DLI received by leaves, growth of leaf areas was different until floral bud initiation. The maximum leaf area was $598 \mathrm{~cm}^{2}$ in $\mathrm{FH}$ treatment, and the minimum leaf area was $490 \mathrm{~cm}^{2}$ in $\mathrm{HL}$ treatment.

Variation of dry matter with floral initiation is shown in Fig. 6. Data in the x-axis represent the days after transplanting (DAT), and the data in the y-axis represent the dry matter in grams. Curves in the graph are the increase of dry matter until floral initiation. The increase of dry matter was different in all treatments, but until the flowering day, the dry matter almost reached the same weight of $3 \mathrm{~g}$. In FH treatment, the increase of dry matter was the fastest, and on the 20th DAT, it reached $3 \mathrm{~g}$, and then the floral bud started flowering. In HL treatment, the increase of dry matter was the slowest, and on the 31st DAT, it reached $3 \mathrm{~g}$ and began flowering.



Fig. 2. Three shading nets used in the experiment.
Similar variations were also found between the leaf area and the time of floral initiation, as shown in Fig. 7. The data in $\mathrm{x}$-axis represent the DAT, and the data in $\mathrm{y}$ axis represent the leaf area in square centimeters. The floral initiation did not begin until the leaf area increased to a certain amount. In $\mathrm{FH}$ treatment, floral initiation was the fastest and began on the 20th DAT with leaf area of $>500 \mathrm{~cm}^{2}$. In HL treatment, floral initiation began on the 30th DAT with leaf area of $\approx 500 \mathrm{~cm}^{2}$. Although there are some small differences in the values of leaf area, the variations were almost the same.

Effect of fertilizer conditions and shading treatments on flowering days. Days to flowering was significantly affected by fertilizer conditions in different shading treatments (Fig. 8). Due to different shading treatments, flowering days were delayed $\approx 2$ weeks in both the high fertilization condition and the low fertilization condition. In the low fertilization condition, the flowering DAT was slightly later than that in the high fertilization condition.

The effect of DLI on days to flowering and bud number. To estimate the effect of DLI on anthesis, volatility of DLI in days to flowering (DF) was calculated from 1 to $7 \mathrm{~d}, 2$ to $8 \mathrm{~d}, 3$ to $9 \mathrm{~d}, 4$ to $10 \mathrm{~d}, 5$ to $11 \mathrm{~d}, 6$ to $12 \mathrm{~d}, 7$ to $13 \mathrm{~d}, 8$ to $14 \mathrm{~d}, 9$ to $15 \mathrm{~d}$, and 10 to $16 \mathrm{~d}$ (Fig. 9). Both DF and bud number (BN) were highly correlated with DLI from 6 to $12 \mathrm{~d}$ before anthesis, which means this period is essential for anthesis in tomato. The volatility of DLI from 8 to $14 \mathrm{~d}, 9$ to $15 \mathrm{~d}$, and 10 to $16 \mathrm{~d}$ had a low correlation to the DF and $\mathrm{BN}$ and the correlation coefficients were not $>0.6$. The volatility of DLI from 1 to $7 \mathrm{~d}, 2$ to $8 \mathrm{~d}$, and 3 to $9 \mathrm{~d}$ had the lowest correlation to the $\mathrm{DF}$ and $\mathrm{BN}$ and the correlation coefficients were not $>0.3$.

The number of buds decreased according to the increase of shading ratio in two fertilizer treatments, but the variation values were different. In full-light conditions, the extent of the decrease in bud number was larger than that in high shading condition. In full-light conditions, the decreases of average bud numbers with high fertilizer treatment was 21 and low fertilizer treatment was 12 . In low-light conditions, the decreases of average bud numbers were not as obvious as those in $70 \%$ shading light condition: the average bud number was 10 buds in the high fertilizer treatment and was nine buds in the low fertilizer treatment. In the low-light intensity conditions, the high fertilizer treatment did not contribute to the increase of bud numbers and the nutrient assimilation of plant was inhibited.

Table 1. Experimental treatments in this study.

\begin{tabular}{lccc}
\hline & \multicolumn{2}{c}{ Fertilization treatment } & \\
\cline { 2 - 4 } Shading treatment & High concn & Low concn & Abbreviation \\
\hline High shading ratio (70\%) & 1.8 unit & 0.6 unit & HH \\
Medium shading ratio (50\%) & 1.8 unit & 0.6 unit & HL \\
Low shading ratio (30\%) & 1.8 unit & 0.6 unit & ML \\
Full light & 1.8 unit & 0.6 unit & LH \\
\hline
\end{tabular}


The position of the first inflorescence varied in all treatments. In the FH treatment, the floral shoot was found above the sixth leaf. In FL, LH, LL, MH, ML, and $\mathrm{HH}$ treatments, floral shoots appeared above the seventh leaf; in the HL treatment, the shoot was on the eighth leaf. Although the number of floral buds was restricted due to shading and fertility treatments, variations of petal and stalks were not obviously at blooming in the greenhouse experiment, as shown in Fig. 10.

Differences in elongation and shape of flower shoots were observed among all treatments. Lengths of flower shoots were significantly different among treatments. In high fertilizer treatment, flower shoots were longer than those in low fertilizer treatment. The

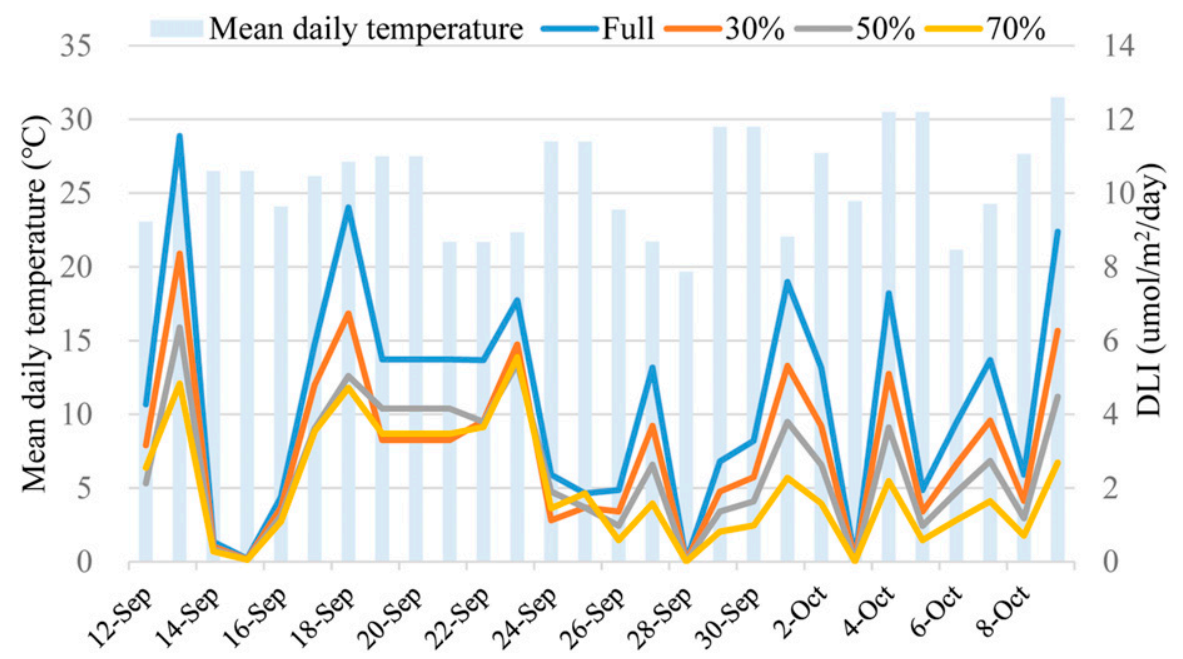

Fig. 3. Variations of daily temperature and daily light integral (DLI) during experiments.

maximum average length of flower shoots was $9.5 \mathrm{~cm}$ in $\mathrm{FH}$ and the minimum value was $6.0 \mathrm{~cm}$ in $\mathrm{HL}$ treatment. All flower shoots formed single shapes except in the FH treatment, where shoots had a doubled shape (Fig. 11).

\section{Discussion}

Adjustments in the source-sink relationship between photosynthetic organs and floral organs. Environmental factors and nutrients heavily influence floral initiation, development, and timing of flowering. Morphological variations with floral initiation were found in number of nodes, branches, leaf structure, and reproduction length in several species (Clerget et al., 2008; Cookson et al., 2007; Davidenco et al., 2017; Iwanami et al., 2018; Nicok et al., 2015; Slafer et al., 1994), showing the adaptation of plants to their environments and the plasticity in plant growth. However, few reports explain the floral initiation with regard to source and sink dynamics or supply and demand of photoassimilates.

Plants produce photoassimilates in leaves as source organs and consume them to develop new leaves, stems, roots, and flower buds, which are referred to as sink organs. Photosynthesis is the most important physiological

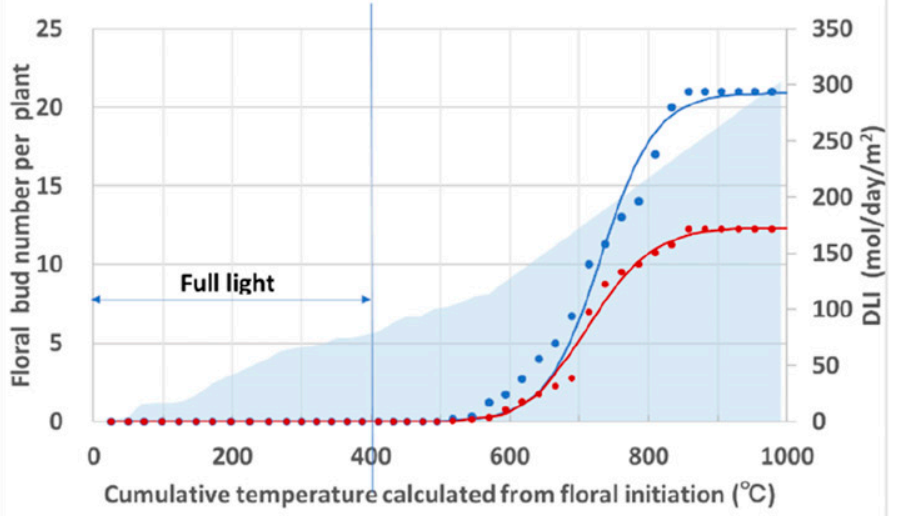

$\mathrm{DL}-\mathrm{OH}-\mathrm{OL} \cdot \mathrm{OH} \cdot \mathrm{OL}$

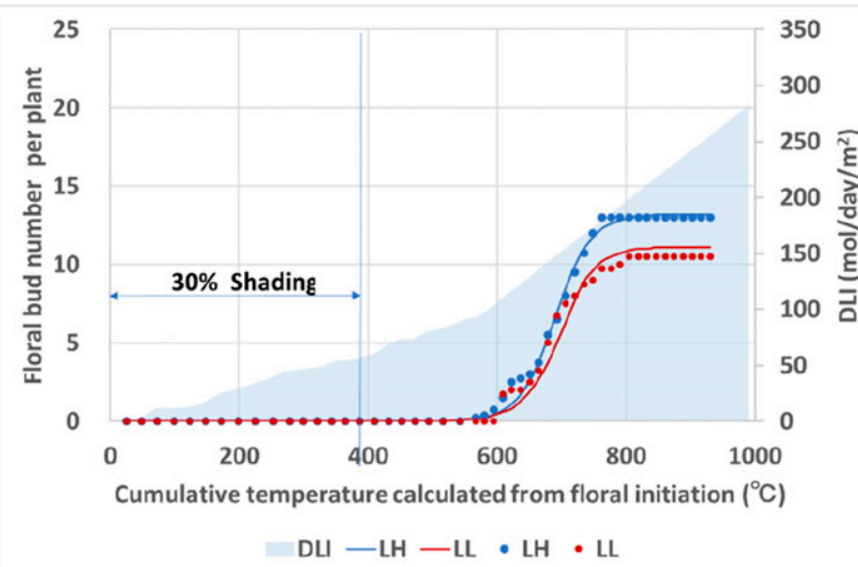



$D \mathrm{DL}-\mathrm{MH}-\mathrm{ML} \cdot \mathrm{MH} \cdot \mathrm{ML}$

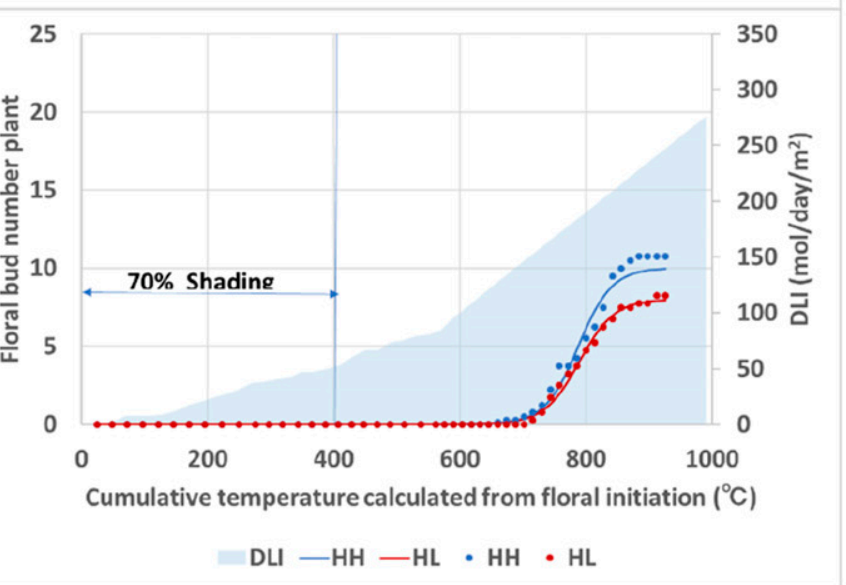

Fig. 4. The sigmoidal logistic curve fitted between floral bud numbers with cumulative temperature and daily light integral (DLI). Values are mean for $\mathrm{n}=8$ replications. 
$\mathrm{HH}$

$\mathrm{MH}$

LH
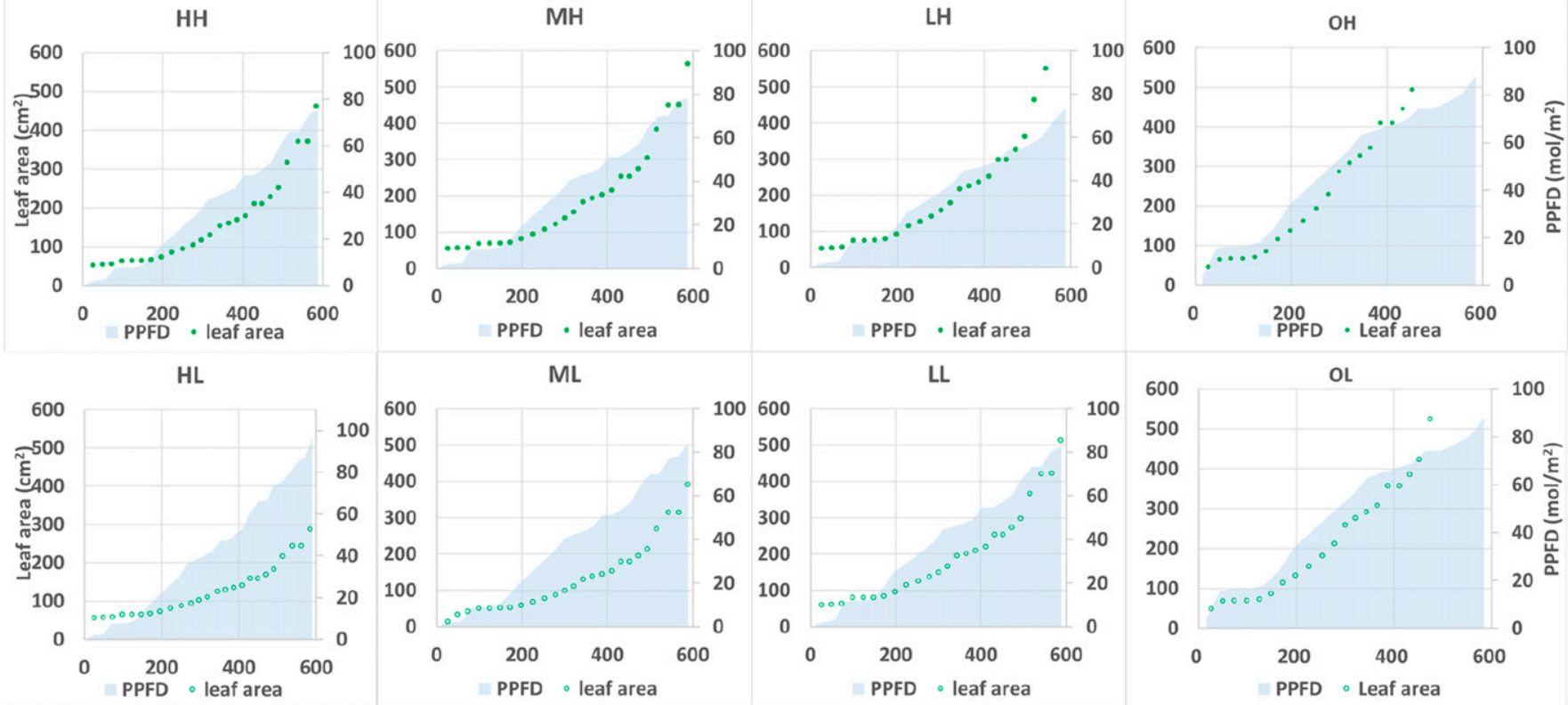

Fig. 5. Variation of leaf area with cumulative temperatures and daily light integral (DLI) until the beginning of flowering. PPFD = photosynthetic photon flux density.

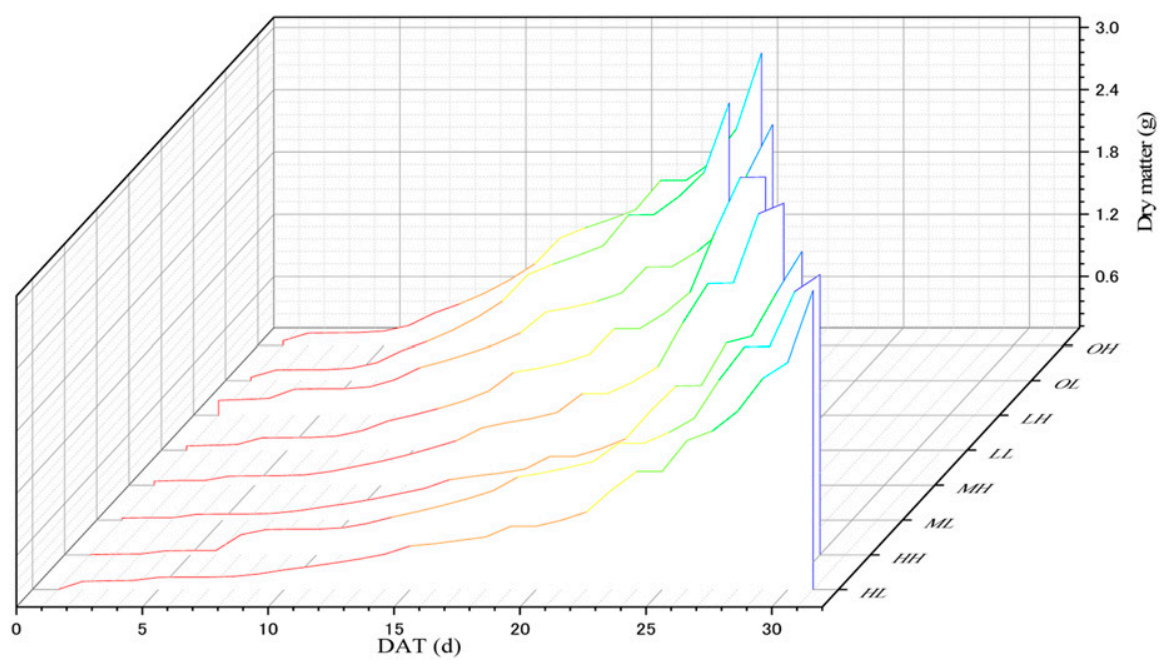

Fig. 6. Variation of dry matter with floral initiation time. DAT $=$ days after transplanting.

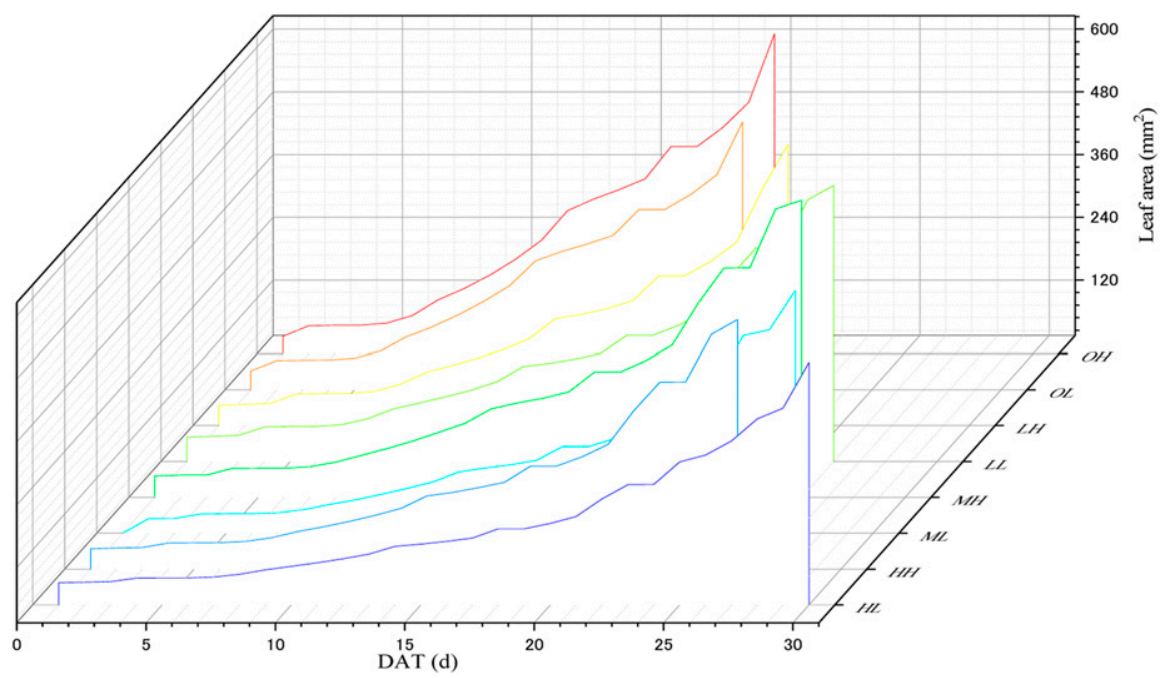

Fig. 7. Variation of leaf area with the time of floral initiation. DAT $=$ days after transplanting. activity for plants to produce biomass and realize the distribution of photoassimilates by the source-sink relationship between the photosynthetic organs and floral organs. Understanding adjustments in the source-sink relationship between photosynthetic organs and floral organs is an essential step toward crop production (Marcelies et al., 1998; Pincovici et al., 2018; Roberson et al., 2002). With this perspective, the greenhouse experiment was conceptualized to investigate whether tomato seedlings have the ability to adapt to variations in light intensity and nutrients during flower initiation and to demonstrate the dynamic source-sink communication between leaves and floral organs.

Variations in leaf area and dry matter before the first flower bud initiation. Dynamic variations in leaf area and dry matter before the first flower bud initiation were observed in different treatments (Figs. 4-7). Differences were noticed in the growth speed of leaf area and the accumulation speed of dry matter. Increasing the shading ratio resulted in the restriction of light interception of tomato seedlings and photosynthetic production decreased. However, total leaf area and dry matter per plant reached similar amounts in each treatment before the flowering day, which is the result of plasticity.

Under the low-light-intensity condition, the daily net carbon assimilation of leaf was slowed, but a quantitative balance between inflorescences and photosynthesis production is essential for the beginning of flowering in the tomato. Thus, our experiments indicate that the amount of leaf area or dry matter is more reasonable than accumulated thermal time for describing the dynamic variations of floral initiation with different light and nutrient treatments. In most studies, the floral initiation was described by the accumulated time or thermal effectiveness, which was 


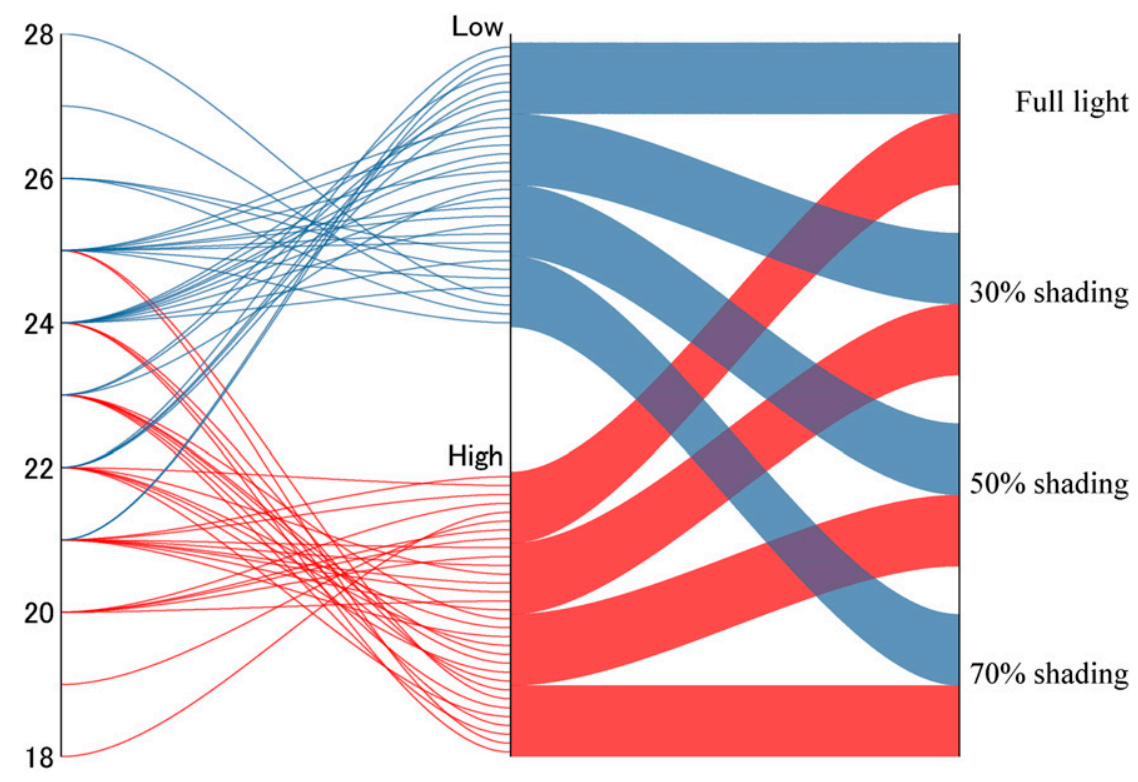

DAT

Fertilization

Light treatment

Fig. 8. Effects of fertilizer conditions and shading treatments during the bud formation period on days to flowering after transplanting (DAT).

A
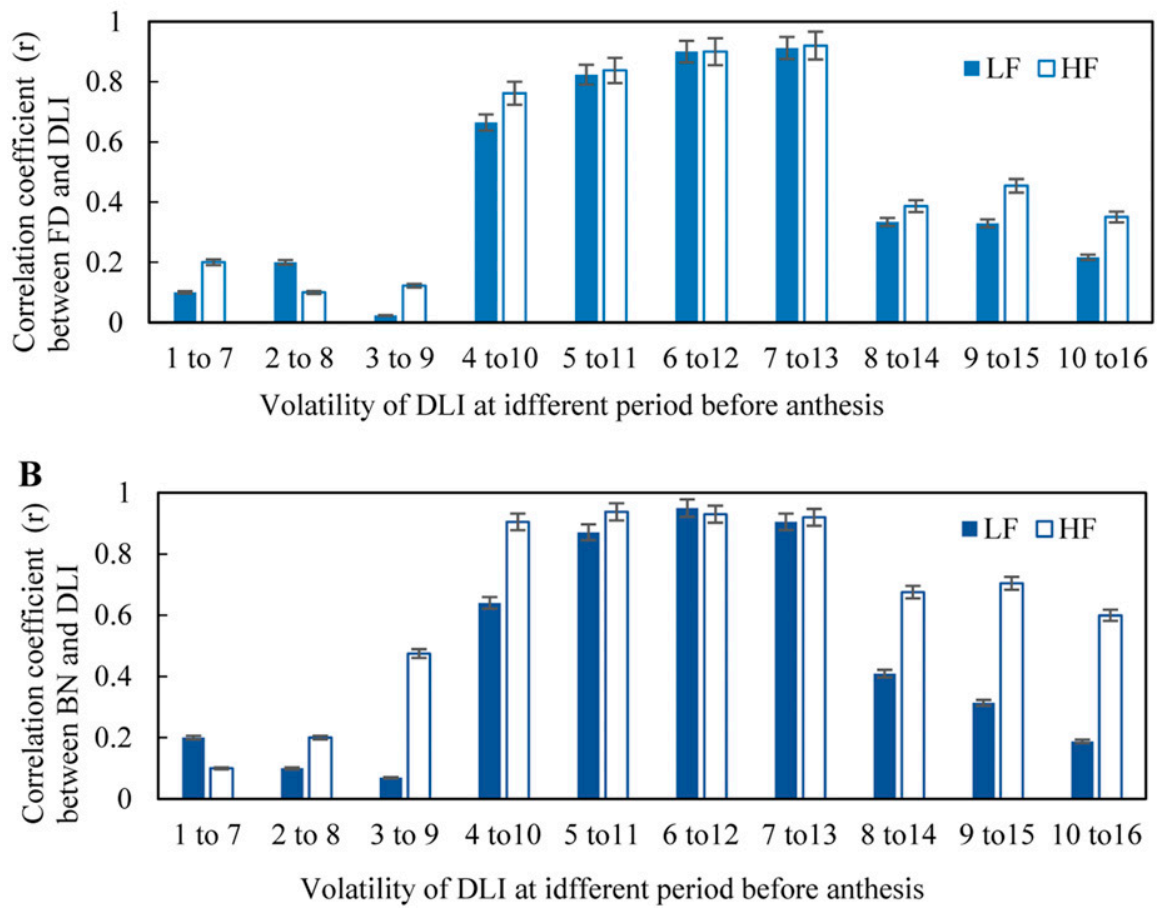

Fig. 9. The effect of daily light integral (DLI) before anthesis under different treatments. (A) Correlation coefficient between days to flowering (DF) and DLI. (B) Correlation coefficient between bud number $(\mathrm{BN})$ and DLI

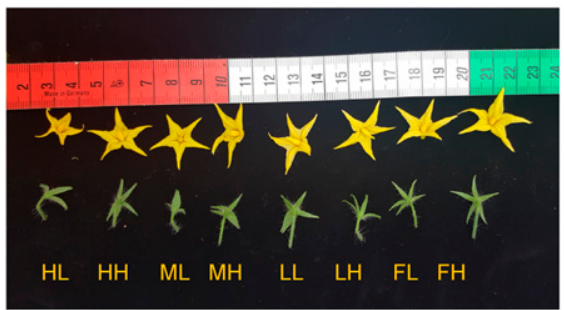

Fig. 10. Floral buds of different treatments at blooming. production (dry matter) or source organs (leaf area).

Leaves act as the source organ and photosynthesize, which is the main supply of starch and sucrose for plant growth and flower nutrition. Before the formation of flower bud, flower formation depends on carbohydrate reallocation from leaves (Lieth and Pasian, 1991; Mao et al., 2017; Nanda et al., 1995; Saito et al., 2015,). Therefore, the initiation of flower buds as the sink organ for biomass produced by leaves was delayed under shading treatments.

Effect of light intensity on floral initiation. In plants, carbon assimilation is heavily dependent on light intensity. Due to shading effects, the slow export of starch and sugar leads to insufficient accumulation of carbohydrates in source organs of buds, which extends floral initiation and decreases the number of buds. On the basis of the sigmoidal logistic curve of floral development, the effects of shading and nutrients on the variations of floral initiation and development were described (Fig. 4). Under optimal temperature conditions, the beginning of floral initiation in $\mathrm{FH}$ treatment was $11 \mathrm{~d}$ earlier than the HL treatment, due to the fast leaf area growth.

In addition, the balance of source production in leaves and sink utilization of carbohydrates is tightly coordinated through internal regulation to adapt development under external stimuli.

Our study showed that the leaf number before the first floral bud initiation was regulated by the interaction between light and nutrient treatments, and the source-sink balance in plants. In FH treatment, due to the full light and adequate fertilizer, there were six leaves, which produced photoassimilates for the first floral initiation. With the increase of shading ratio from $30 \%$ to $70 \%$, the leaf number increased to seven leaves in ML and $\mathrm{MH}$ treatments and to eight in HL condition. The interaction patterns between leaves and flower buds indicated that when the low light intensity limits photosynthesis and the amount of photoassimilates is insufficient to meet the demand of bud formation, plants can form new leaves to increase source organ and thus increase photosynthesis until it meets the demand for bud formation. Results show that with decreasing light intensity, the leaf number increased, supporting the findings that the leaf number was positively related to days from transplanting to floral initiation (Dileman and Heuvelink, 1992; Nesmith, 1997; Sezgin, 2006). This result is similar to the source-sink relationship among leaves and fruits and among different parts of fruits (Olesen et al., 2002; Prudent et al., 2014).

Effect of nutrient on floral initiation. The effect of nutrient availability on the growth of plants has been extensively researched (Moustakas and Ntzanis, 2005). Reduced photosynthesis and leaf nitrogen content were found in the shaded plants, highlighting the adaption of plants under low light intensity (Gallagher et al., 2015). However, previous 

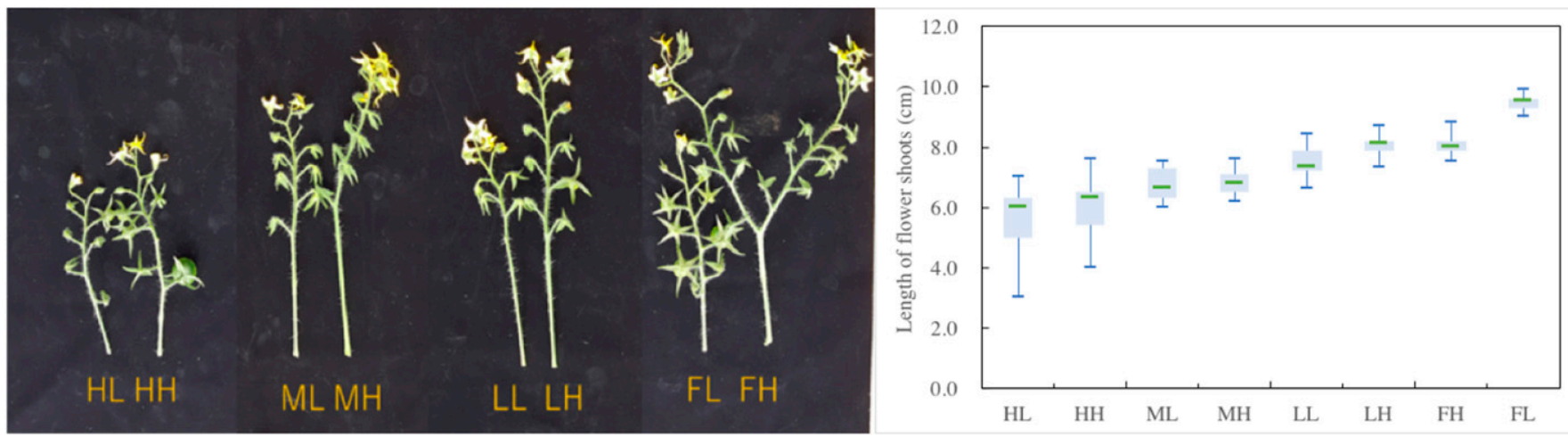

Fig. 11. Length of flower shoots under different treatments.

research has focused on the effect of $\mathrm{N}$ on the biomass production and leaf area, with minimal attention to the relationship between floral initiation and $\mathrm{N}$ availability. Examining our findings, fertilizer provides direct nutrients for seedlings and has a positive effect on the number of buds. The low concentration of nutrients resulted in a $40 \%$ decrease in bud number compared with the high concentration of fertilizer. This was also shown in other studies in the form of dry matter variation and nutrient distribution (Gijzen et al., 1998).

The absorption of nutrients was restricted by light environment. In the full light condition, the differences in average bud numbers between high and low fertilizer treatments were obvious. In the low-light condition, the decrease of average bud numbers by shading was not as obvious as those in high-light condition. The average bud number was 10 buds in high fertilizer treatment and nine buds in low fertilizer treatment. In the lowlight-intensity conditions, high fertilizer treatment did not contribute to the increase in bud numbers, and the nutrient assimilation of the plant was inhibited. This can also be explained by the fact that the carbon assimilation decreased in the high shading condition and the low carbon to nitrogen ratio led to the decrease in bud numbers. In the high shade treatment, the nutrition absorption of tomato was restricted by light condition. These findings suggest that light was an important signal during floral initiation and accumulated light acts upstream of nutrition supply in this experiment. These results are in agreement with previous research by Furet et al. (2014)

During the experiment, after removing shading nets, there was no variation in numbers of buds, which means the determination of bud number is an irreversible course. The shading effects on the bud number will thus not be removed even if the experimental tomato seedling is receives full light condition after earlier shading. There are some reports about variations in climatic conditions and water causing variation in genes related with the bud in fruit trees, such as peaches, apples, and Japanese pears (Faust et al., 1991; Fennell, 2001; Yamamoto et al., 2010; Yooyongwech et al., 2008). There was no obvious change, however, in the size of buds in the current study, which may be because tomato seedlings cultivated in this experiment had adequate water.

\section{Conclusions}

In this study, the dynamic coordination of tomato seedlings to capture energy and nutrients on development of floral initiation was investigated. The floral development model accurately described the floral initiation in response to accumulated temperature, which can be used to predict the time of floral initiation and the development of the floral rate. During the floral initiation and development, tomato gained energy from photosynthesis in source organs, mainly leaves, and transferred the photoassimilates to sink organs for utilization. Evaluation of the dynamic variation of leaf area and dry matter revealed that some amount of photoassimilates is necessary for floral initiation. Accumulated light acts upstream of nutrition supply during the formation of bud and leads to the accumulation of carbohydrates in source organs. Both days to flowering and bud number were highly correlated with DLI from 6 to $12 \mathrm{~d}$ before anthesis, which means this period is important for tomato anthesis. By variations in sink strength or low nutrition conditions, the growth of tomato seedlings will adjust floral positions, length of floral shoots, floral initiation days, and leaf numbers to adapt to environmental variation. Quantifying the effects of the source-sink relationship on the photoassimilates and floral initiation is a crucial step to balance growth from the vegetative to reproductive stages in tomato, which provides new insights to promote floral initiation and achieve a high yield potential.

\section{Literature Cited}

Blackman, B.K. 2017. Changing responses to changing seasons: Natural variation in the plasticity of flowering time. Plant Physiol. 173:16-26.

Brøndum, J.J. and R.D. Heins. 1993. Modelling temperature and photoperiod effects on growth and development of dahlia. J. Amer. Soc. Hort. Sci. 118:36-42.

Chen, H., Q. Zhang, Z. Lu, and F. Xu. 2018 Accumulation of ammonium and reactive oxygen mediated drought-induced rice growth inhi- bition by disturbed nitrogen metabolism and photosynthesis. Soil Sci. 431:107-117.

Christiaens, A., E.D. Keyser, E. Pauwels, J.D. Riek, B. Gobin, and M.V. Labeke. 2016. Suboptimal light conditions influence source-sink metabolism during flowering. Front. Plant Sci. $7: 1-11$.

Clerget, B., M. Dingkuhn, E. Goze, H. Rattuned, and B. Ney. 2008. Variability of phyllochron, plastochron and rate of increase in height in photoperiod-sensitive Sorghum varieties. Ann. Bot. 101:579-594.

Cookson, S.J., K. Chenu, and C. Granier. 2007. Day length affects the dynamics of leaf expansion and cellular development in Arabidopsis thaliana partially through flora transition timing. Ann. Bot. 99:703-711.

Corbesier, L., P. Lejeune, and G. Bernier. 1998. The role of carbohydrates in the induction of flowering in Arabidopsis thaliana: Comparison between the wild type and a starchless mutant. Planta 206:131-137.

Davidenco, V., J.A. Arguello, M.B. Piccardi, and C.R.C. Vega. 2017. Day length modulates precocity and productivity through its effect on development rate in Origanum vulgare $\mathrm{sp}$. HortScience 218:164-170.

Dileman, J.A. and E. Heuvelink. 1992. Factors affecting the number of leaves preceding the first inflorescence in tomato. HortScience 67: $1-10$.

Faust, M., D. Liu, M.M. Millard, and G.W. Stutte. 1991. Bound versus free water in dormant apple buds - a theory for endodormancy. HortScience 26:887-890

Fennell, A. 2001. Line MJ Identifying differential tissue response in grape (Vitis riparia) during induction of endodormancy using nuclear magnetic resonance imaging. J. Amer. Soc. Hort. Sci. 126:681-688.

Fudano, T., T. Hahashi, and S. Yazawa. 2009. Dynamic model of dry distribution and stabilization in the number of buds per inflorescence by overnight supplemental lighting in sweet pea (Lathyrus odoratus L.). J. Jpn. Soc. Hort. Sci. 78:344-349.

Furet, P.M., J. Lothier, S. Demotes-Mainard, S. Travier, C. Henry, V. Guérin, and A. Vian. 2014. Light and nitrogen nutrition regulate apical control in Rosa hybrid L. J. Plant Physiol. 171:7-13.

Gallagher, E., K.W. Mudge, M.P. Pritts, and S.D. Degloria. 2015. Growth and development of "Illini Hardy" blackberry (Rubus subgenus Eubatus Focke) under shaded systems. Agrofrest Syst. 89:1-17.

Gao, X., H. Endo, and Y. Agatsuma. 2018. Seasonal changes in photosynthesis, growth, 
nitrogen accumulation, and salinity tolerance of Chaetomorpha crassa (Cladophorales, Chlorophyceae). J. Appl. Phycol. 30:19051912.

Gijzen, H., E. Heuvelink, H. Challa, L.F.M. Marcelis, E. Dayan, and S. Cohen. 1998. Hortisim: A model for greenhouse crops and greenhouse climate. Acta Hort. 456:441-450.

Gonzalez-Real, M.M., A. Baille, and H.Q. Liu. 2008. Influence of fruit load on dry matter and $\mathrm{N}$-distribution in sweet pepper plants. HortScience 117:307-315.

Gotoh, E., N. Suetsugu, W. Yamori, K. Ishishita, R. Kiyabu, M. Fukuda, T. Higa, B. Shirouchi, and M. Wadae. 2018. Chloroplast accumulation response enhances leaf photosynthesis and plant biomass production. Plant Physiol. 178:1358-1369.

Heuvelink, E. and L.F.M. Marcelis. 1996. Influence of assimilate supply on leaf formation in sweet pepper and tomato. J. Hort. Sci. 71:405414.

Illangakoon, T.K. and H. Bandara. 2004. Evaluation of physio-agronomic and chemical traits in relation to the productivity of eggplant ( $\mathrm{So}$ lanum melongena L.). Trop. Agr. Res. 16:1424.

Iwanami, H., Y. Moriya-Tanaka, C. Honda, T. Hanada, and M. Wada. 2018. A model for representing the relationships among crop load, timing of thinning, flower bud formation, and fruit weight in apples. HortScience 242:181187.

Kawakatsu, K., T. Harada, A. Ushio, M. Dozono, and N. Fukuta. 2017. Thermal control suitable for increasing petals in Eustoma grandiflorum (Raf.) Shinn. Hort. J. 87:389-394.

Kinet, J.M. 1977. Effects of light conditions on the development of the inflorescence in tomato. HortScience 6:15-26.

Kumar, N., G.C. Srivastava, and K. Dixit. 2008. Role of sucrose synthase and invertases during petal senescence in rose (Rosa hybrida L.). J. Hort. Sci. Biotechnol. 83:520-524.

Lee, J., J. Goudriaan, and H. Challa. 2003. Using the expolinear growth equation for modelling crop growth in year-round cut chrysanthemum. Ann. Bot. 92:697-708.

Li, T., E. Heuvelink, and L.F.M. Marcelis. 2015. Quantifying the source-sink balance and carbohydrate content in three tomato cultivars. Front. Plant Sci. 6:1-10.

Lieth, J.H. and C.C. Pasian. 1991. A simulation model for the growth and development of flowering rose shoots. HortScience 46:109128.

Luo, T., J. Zhang, M. Khan, J. Liu, Z. Xu, and L. Hu. 2018. Temperature variation caused by sowing dates significantly affects floral initiation and floral bud differentiation processes in rapeseed. Plant Sci. 271:40-51.

Mao, T., J. Li, and Z. Wen. 2017. Association mapping of loci controlling genetic and environmental interaction of soybean flowering time under various photo-thermal conditions. BMC Genomics 18:2-17.

Marcelis, L.F.M., E. Heuvelink, and J. Goudriaan. 1998. Modelling biomass production and yield of horticultural crops: A review. HortScience 74:83-111.

Marcelis, L.F.M. and H. Gijzen. 1998. A model for prediction of yield and quality of cucumber fruits. Acta Hort. 476:237-242.

Marion, P., W. Zhan, G. Michel, B. Nadia, C. Mathilde, and V. Philppe. 2014. Resource competition modulates the seed number-fruit size relationship in a genotype-dependent manner: A modeling approach in grape and tomato. Ecol. Modell. 290:54-64.

Moustakas, N.K. and H. Ntzanis. 2005. Dry matter accumulation and nutrient uptake in flue-cured tobacco (Nicotiana tabacum L.). Field Crops Res. 94:1-13.

Nanda, R., S.C. Bhargava, and H.M. Rawson. 1995. Effect of sowing date on rates of leaf appearance, final leaf numbers and areas in Brassica campestries, B. juncea, B. napus, and B. carinata. Field Crops Res. 42:125-134.

NeSmith, D.S 1997. Summer squash (Cucurbita реро L.) leaf number as influenced by thermal time. HortScience 68:219-225.

Nicok, M., A.I. Mantese, D.J. Miralles, and A.G. Kantolic. 2015. Soybean fruit development and set at the node level under combined photoperiod and radiation conditions. J. Expt. Bot. 67:365-377.

Olesen, J.E., B.M. Petersen, J. Berntsen, S. Hansen, P.D. Jamieson, and A.G. Thomsen. 2002. Comparison of methods for simulating effects of nitrogen on green area index and dry matter growth in winter wheat. Field Crops Res. 74:131-149.

Pincovici, S., A. Cochavi, A. Karnieli, J. Ephrath, and S. Rachmilevitch. 2018. Source-sink relations of sunflower plants as affected by a parasite modifies carbon allocations and leaf traits. Plant Sci. 271:100-107.

Prudent, M., W. Zhan, M. Genar, N. Bertin, M. Causse, and P. Vivin. 2014. Resource competition modulates the seed number-fruit size relationship in a genotype-dependent manner: A modeling approach in grape and tomato. Ecol. Modell. 290:54-64.

Roberson, M.J., S. Asseng, J.A. Kirkegaard, N. Wratten, J.F. Holland, A.R. Watkinson, T.D. Potter, W. Burton, G.H. Walton, D.J. Moot, and I. Farre. 2002. Environmental and genotypic control of time to flowering in canola and Indian mustard. J. Agr. Res. 53:793-809.

Roldán, M., C. Gómez-Mena, L. Ruiz-García, J. Salinas, and J.M. Martínez-Zapater. 1999. Sucrose availability on the aerial part of the plant promotes morphogenesis and flowering of Arabidopsis in the dark. Plant J. 20:581-590.

Saito, T., P.A. Tuan, A. Katsumi-Horigane, S. Bai, A. Ito, Y. Sekiyama, H. Ono, and T. Moriguchi. 2015. Development of flower buds in the Japaneses pear (Pyrus pyrifolia) from late autumn to early spring. Tree Physiol. 35:653662.

Sezgin, U. 2006. The quantitative effects of temperature and light on the number of leaves preceding the first fruiting inflorescence on the stem of tomato (Lycopersicon esculentum, Mill.) and aubergine (Solanum melongena L.). HortScience 109:142-146.

Slafer, G.A., D.J. Connor, and G.M. Halloran. 1994. Rate of leaf appearance and final number of leaves in wheat: Effects of duration and rate of change of photoperiod. Ann. Bot. 74:427436.

Tomer, M.B., E. Shemesh-Mayer, K.S.G. Chen, I. Forer, V.T. Aila, H.D. Rabinowitch, and R.K. Goldstein. 2018. Temporal and spatial effect of low pre-planting temperatures on plant architecture and flowering in bolting garlic. HortScience 242:69-75.

Villalobos, F.J. and J.T. Ritchie. 1992. The effect of temperature on leaf emergence rates of sunflower genotypes. Field Crops Res. 29:3746.

Xu, R., J. Dai, W. Luo, X. Yin, Y. Li, X. Tai, L. Han, Y. Chen, L. Lin, G. Li, C. Zou, W. Du, and M. Diao. 2010. A photothermal model of leaf area index for greenhouse crops. Agr. For. Meteorol. 150:541-552.

Yamamoto, R.R., A. Katsumi-Horigane, M. Yoshida, Y. Sekozawa, S. Sugaya, and H. Gemma. 2010. "Floral primordia necrosis" incidence in mixed buds of Japanese pear [Pyrus pyrifolia (Burm.) Nakai var. culta] 'Housui' grown under mild winter conditions and the possible relation with water dynamics. J. Jpn. Soc. Hort. Sci. 79:246-257.

Yap, Y., C. Loh, and B. Ong. 2008. Regulation of flower development in Dendrobium crumenatum by changes in carbohydrate contents, water status and cell wall metabolism. HortScience 119:59-66.

Yasuoka, J.I., C.G.S. Pedreira, V.J. Silva, M.P. Alonso, L.S. Silva, and F.J. Gomes. 2018 Canopy height and $\mathrm{N}$ affect herbage accumulation and the relative contribution of leaf categories to photosynthesis of grazed brachiaria grass pastures. Grass Forage Sci. 73:183192.

Yooyongwech, S., A.K. Horigane, M. Yoshida, M. Yamaguchi, Y.S. Sugaya, and H. Gemma. 2008. Changes in aquaporin gene expression and magnetic resonance imaging of water status in peach tree flower buds during dormancy. Physiol. Plant. 134:522-533.

Yu, S., S. Lo, and Y. Ho. 2015. Source-sink communication: Regulated by hormone, nutrient, and stress cross-signaling. Trends Plant Sci. 20:844-857.

Zhang, C., B. Feng, T. Chen, W. Fu, H. Li, G. Li, Q. Jin, L. Tao, and F. Guan. 2018. Heat stressreduced kernel weight in rice at anthesis is associated with $\mathrm{T}$ impaired source-sink relationship and sugars allocation. Environ. Exp. Bot. 155:718-733. 